\title{
Fracture Resistance Enhancement in Hard Mo-B-C Coatings Tailored by Composition and Microstructure
}

\author{
Pavel Soucek (D), ${ }^{1}$ Lukas Zabransky (D), ${ }^{1}$ Vilma Bursikova, ${ }^{1}$ Jiri Bursik (D), \\ Stanislava Debnarova, ${ }^{1}$ Milan Svoboda $\left(\mathbb{1},{ }^{2}\right.$ Vratislav Perina, ${ }^{3}$ and Petr Vasina $\left(\mathbb{1}{ }^{1}\right.$ \\ ${ }^{1}$ Department of Physical Electronics, Faculty of Science, Masaryk University, Kotlarska 2, 61137 Brno, Czech Republic \\ ${ }^{2}$ Institute of Physics of Materials, Academy of Sciences of the Czech Republic, Zizkova 22, 61662 Brno, Czech Republic \\ ${ }^{3}$ Nuclear Physics Institute, Academy of Sciences of the Czech Republic, v.v.i., Rez 130, 25068 Rez, Czech Republic \\ Correspondence should be addressed to Pavel Soucek; soucek@physics.muni.cz
}

Received 8 September 2017; Revised 19 December 2017; Accepted 7 February 2018; Published 14 March 2018

Academic Editor: Albano Cavaleiro

Copyright (C) 2018 Pavel Soucek et al. This is an open access article distributed under the Creative Commons Attribution License, which permits unrestricted use, distribution, and reproduction in any medium, provided the original work is properly cited.

\begin{abstract}
State-of-the-art protective coatings often suffer from brittleness. Therefore, the coatings are intensively sought which would simultaneously exhibit high hardness and stiffness with moderate ductility and fracture resistance. In this paper, we report on the nanostructure designing of coatings containing metal, boron, and carbon enabling the simultaneous presence of stiff boridic and carbidic bonds together with weaker metallic bonds to provide coatings with these desirable properties. Three designs are presented with different relative amounts of nanocrystalline and amorphous phases, ranging from near-amorphous to prevalently crystalline microstructure. All presented coatings exhibit an unusual combination of high fracture resistance and high hardness that cannot be achieved with state-of-the-art protective coatings. Indentation tests at high loads revealed that no cracks are present at the surface of the investigated coatings while state-of-the-art ceramic protective coatings already exhibit significant cracking. Cracks in the bulk of the presented coating are detected only when the deformation is so severe that the substrate itself fails.
\end{abstract}

\section{Introduction}

Cutting edge commercially available hard protective coatings generally exhibit high hardness and stiffness which is usually accompanied by brittle deformation behavior. Therefore, a crack is formed easily and its subsequent rapid propagation can lead to premature failure of the coating and, consequently, of the workpiece itself. Nowadays, it is of high interest to design next-generation protective coatings with an unusual combination of physical properties: high hardness and stiffness together with sufficient fracture resistance. Coatings with such unique features should be able to withstand applications under severe conditions where the nowadays used state-of-the-art protective coatings fail rapidly.

Recently, a group of unusually stiff and fracture resistant hard coatings was proposed based on theoretical calculations [1, 2]. Different combinations of metal-, boron-, and carbon-based materials were studied by ab initio calculations. The most promising candidates according to the calculations were $\mathrm{Mo}_{2} \mathrm{BC}, \mathrm{W}_{2} \mathrm{BC}$, and $\mathrm{Ta}_{2} \mathrm{BC}$, each with predicted
Young's modulus higher than $420 \mathrm{GPa}$. These materials owe their unique combination of mechanical properties to their inherently nanolaminated microstructure. They exhibit high aspect ratio unit cell that is similar to MAX phases with alternating planes containing stiff carbidic and boridic bonds with a high degree of ionicity providing the high stiffness and hardness, while metallic bonds offer moderate ductility.

Mechanical properties of coatings can also be enhanced by preparing them in a nanocomposite form. Nanocomposites can exhibit enhanced hardness and toughness [3] due to their microstructure and the physical effect of nanocomposite hardening [4] or an effect similar to the Hall-Petch effect $[5,6]$. Additionally, grain sliding, which is a form of plastic deformation, occurs in nanocomposites. It can suppress the crack formation, thereby leading to an enhancement of the fracture resistance $[7,8]$.

In this paper, a strategy of varying the microstructure and the composition of Mo-B-C coatings is utilised for the synthesis of coatings with high hardness and fracture resistance. Three coatings with a distinctly different chemical 
TABLE 1: Deposition conditions, chemical composition, and the thickness of the deposited coatings.

\begin{tabular}{|c|c|c|c|c|c|c|c|c|c|c|c|}
\hline \multirow{2}{*}{ Coating type } & \multicolumn{3}{|c|}{ Power [W] } & \multirow{2}{*}{ Pressure $[\mathrm{Pa}]$} & \multirow{2}{*}{ Temperature $\left[{ }^{\circ} \mathrm{C}\right]$} & \multirow{2}{*}{ Bias $[\mathrm{V}]$} & \multirow{2}{*}{ Time [min] } & \multicolumn{3}{|c|}{ Composition [at.\%] } & \multirow{2}{*}{ Thickness $[\mu \mathrm{m}]$} \\
\hline & Mo & $\mathrm{B}_{4} \mathrm{C}$ & $\mathrm{C}$ & & & & & Mo & $\mathrm{B}$ & $\mathrm{C}$ & \\
\hline $\mathrm{A}$ & 110 & 128 & 250 & 0.1 & 40 & - & 480 & 52 & 24 & 24 & 1.2 \\
\hline $\mathrm{B}$ & 110 & 128 & 250 & 0.1 & 500 & - & 480 & 52 & 24 & 24 & 1.5 \\
\hline $\mathrm{C}$ & 91 & 128 & 278 & 0.1 & 40 & -200 & 480 & 65 & 23 & 12 & 0.8 \\
\hline
\end{tabular}

and phase compositions are shown. Particular focus is given to the study of their microstructure and the evaluation of their mechanical properties. The fracture resistance of the deposited coatings is qualitatively evaluated and compared to the state-of-the-art protective coatings. It is concluded that the fracture resistance was significantly improved, while preserving the hardness.

\section{Experimental Details}

All depositions were carried out using Vinci Technologies PVD 50S sputtering device with a cylindrical chamber $0.5 \mathrm{~m}$ in diameter and $0.5 \mathrm{~m}$ in height with an attached loadlock system for sample transfer. The chamber and the loadlock were evacuated by separate turbomolecular pumps backed by scroll pumps to a base pressure in the order of $10^{-5} \mathrm{~Pa}$. The chamber was equipped with four planar circular magnetron heads with a well-balanced magnetic field. Threeinch molybdenum (purity 99.95\%, Kurt J. Lesker), carbon (graphite, purity 99.999\%, Kurt J. Lesker), and $\mathrm{B}_{4} \mathrm{C}$ (purity 99.5\%, Kurt J. Lesker) targets were used for all experiments. Molybdenum and $\mathrm{B}_{4} \mathrm{C}$ targets were driven by Maxim 1000 DC generators from Power Mag Technologies; carbon target was driven by Pinnacle plus bipolar pulsed-DC generator from Advanced Energy. All magnetron heads were focused on a single substrate holder in a sputter-down configuration. The target to substrate distance was $18 \mathrm{~cm}$. Such a high target to substrate distance was chosen in order to achieve good homogeneity of the deposited coatings. The sample holder could be simultaneously rotated, biased, and heated up to $750^{\circ} \mathrm{C}$. Argon (purity $99.999 \%$, Messer) was used as a working gas and was dosed via a mass flow controller. The pressure could be set independently on the gas flow by a butterfly valve in front of the turbomolecular pump.

Cemented tungsten carbide and glassy carbon substrates were first ultrasonicated in acetone and isopropyl alcohol baths. Then they were loaded into the chamber and placed onto the substrate holder via a load-lock without breaking the vacuum in the deposition chamber. When heating was used for type $\mathrm{B}$ and $\mathrm{C}$ coatings, the heating was turned on and set to $500^{\circ} \mathrm{C}$, and the substrates were heated up for 120 min to stabilize the temperature. Afterwards, the argon flow of $6 \mathrm{sccm}$ was introduced, and the pressure of $0.3 \mathrm{~Pa}$ was set. Radiofrequency $(13.56 \mathrm{MHz})$ discharge at the voltage of $-200 \mathrm{~V}(\sim 110 \mathrm{~W})$ was ignited for 20 minutes to ion-clean the substrates. After this time, the shutter over the substrates was closed, and powers delivered to the sputtered cathodes were ramped to the desired values-110 $\mathrm{W}$ for molybdenum, $128 \mathrm{~W}$ for $\mathrm{B}_{4} \mathrm{C}$, and $250 \mathrm{~W}$ for $\mathrm{C}$ target for type $\mathrm{A}$ and $\mathrm{B}$ coatings deposited without self-bias. Type $\mathrm{C}$ coating was prepared with $-200 \mathrm{~V}$ RF bias and $91 \mathrm{~W}$ delivered to the Mo target, $128 \mathrm{~W}$ to the $\mathrm{B}_{4} \mathrm{C}$ target, and $178 \mathrm{~W}$ to the $\mathrm{C}$ target. The pulsing frequency of $350 \mathrm{kHz}$ at $65 \%$ duty cycle was used in all depositions to maximise the ion current onto the substrate [9-11]. The deposition pressure was set to $0.1 \mathrm{~Pa}$ and after the discharge voltage was stabilized the substrate rotation was turned on and set to the rate of $5 \mathrm{rpm}$. Then the shutter over the substrates was opened, and the deposition itself took place for $480 \mathrm{~min}$. After this time, the shutter was closed, and the target powers were gradually ramped down. If heating was used, the temperature was slowly decreasing for several hours. The deposition conditions, the thicknesses, and the chemical composition of the deposited coatings are summarised in Table 1.

Grazing angle of incidence X-ray diffraction (GIXRD) measurements measured by Rigaku Smartlab diffractometer with copper $\mathrm{K}$-alpha radiation $(\lambda=1.54056 \AA)$ at the angle of incidence of $0.5^{\circ}$ were used to evaluate the crystallinity of the coatings. Grazing angle of incidence configuration was used to eliminate peaks from the cemented tungsten carbide substrate. Rutherford backscattering spectroscopy (RBS) was used for the quantification of the chemical composition. The RBS was measured by proton projectiles with energies of 1740 and $2700 \mathrm{keV}$ impinging vertically on the samples, and backscattered protons were analysed at the scattering angle of $170^{\circ}$. The energy is characteristic for the mass of the struck atoms and is also diminished by energy loses by passing of the protons into and out of the layer material [12]. The microstructure of the coatings was studied using Tescan LYRA 3XMU FEG/SEM $\times$ FIB scanning electron microscope (SEM), Philips CM12 STEM transmission electron microscope (TEM), and JEOL JEM 2100F high-resolution TEM. Thin lamellar cross sections for TEM observations were prepared using a focused ion beam (FIB) in the SEM from two locations in each sample: an undisturbed layer and a central region of residual indentation imprint which was made using Fischerscope H100 instrumented indentation tester equipped with Berkovich tip (tip radius $\sim 200 \mathrm{~nm}$ ). The applied load in the case of the Mo-B-C coating and the hard industrially available state-of-the-art protective coatings was always $1 \mathrm{~N}$, and the load increase was controlled according to function $L$ $=C t^{2}$, where $L$ is the load, $t$ is the time, and $C=2.5 \mathrm{mNs}^{-2}$. The hardness and the effective elastic modulus of the coatings were characterised by nanoindentation experiments using Hysitron dual head TI950 Triboindenter equipped with a diamond Berkovich tip (tip radius $<50 \mathrm{~nm}$ ). The mounted nanoscale measuring head with the resolution of $1 \mathrm{nN}$ and load noise floor lower than $30 \mathrm{nN}$ allows for measuring in the load range from $50 \mu \mathrm{N}$ to $11 \mathrm{mN}$. The quasistatic indentation test with 20 partially unloading segments enabled a reliable 


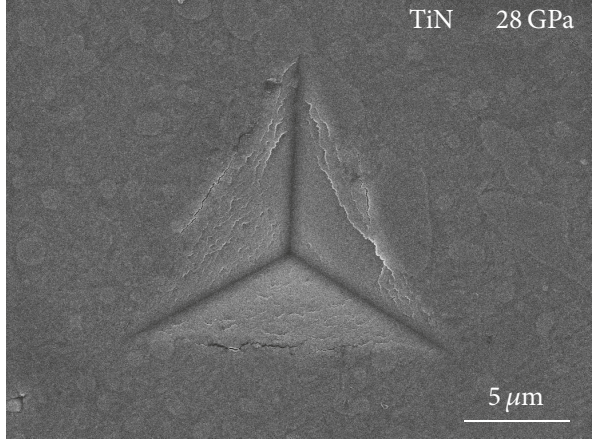

(a)

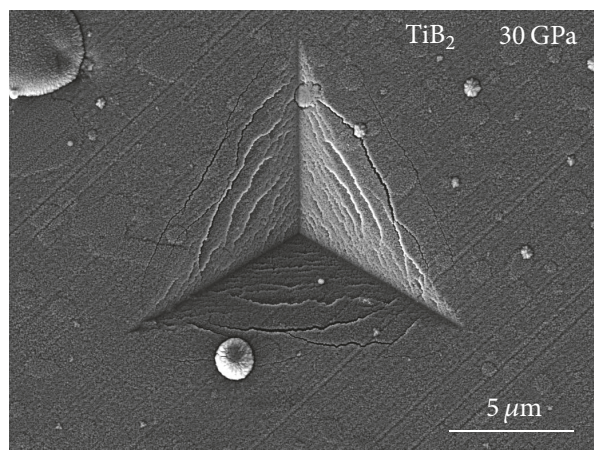

(c)

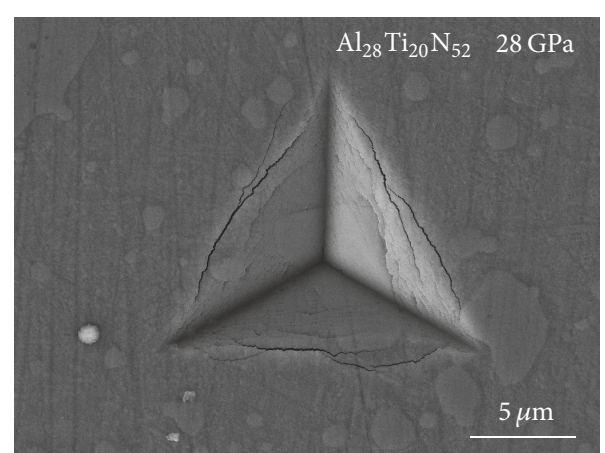

(b)

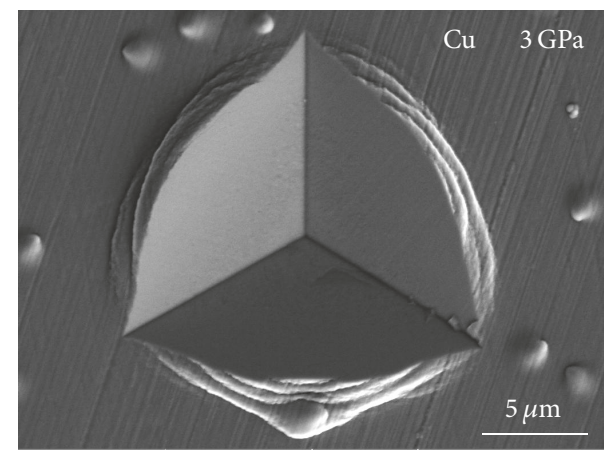

(d)

Figure 1: Residual imprints after indentation tests made into identically thick coatings of (a) TiN, (b) $\mathrm{Al}_{28} \mathrm{Ti}_{20} \mathrm{~N}_{52}$, (c) $\mathrm{TiB}_{2}$, and (d) Cu. TiN, $\mathrm{Al}_{28} \mathrm{Ti}_{20} \mathrm{~N}_{52}$, and $\mathrm{TiB}_{2}$ coatings were indented with the load of $1 \mathrm{~N}$; the more softer copper coating was indented with much lower load to obtain similar indentation depth as in the hard TiN, $\mathrm{Al}_{28} \mathrm{Ti}_{20} \mathrm{~N}_{52}$, and $\mathrm{TiB}_{2}$ coatings.

evaluation of the hardness and elastic modulus from a region of indentation depths $(\sim 80 \mathrm{~nm})$ without the influence of the substrate or surface effects to be performed. The values of the hardness and the elastic modulus were calculated according to the standard procedure proposed by Oliver and Pharr [13]. To ensure proper contact with the surface a small preload of $2 \mu \mathrm{N}$ was used in case of all tests. The indenter tip calibration was carried out for low loads (indentation depths $<100 \mathrm{~nm}$ ). The load of $5 \mathrm{mN}$ was used for the calculation of the ratio of the elastic work to the total indentation work as this corresponded to indentation depths, where the effect of the substrate was again minimal.

\section{Results and Discussion}

Residual imprints after indentation with $1 \mathrm{~N}$ load on commercially produced state-of-the-art protective coatings are shown in Figures 1(a), 1(b), and 1(c). TiN (1.2 $\mu \mathrm{m}$ thick, dense columnar structure, Fm $3 \mathrm{~m}$ cell with lattice parameter of $4.276 \AA$, grain size of $\sim 16 \mathrm{~nm}$, and effective elastic modulus of $600 \mathrm{GPa}$ ) shown in Figure 1(a) with the hardness of $28 \mathrm{GPa}$ and $\mathrm{Al}_{28} \mathrm{Ti}_{20} \mathrm{~N}_{52}$ (1.2 $\mu \mathrm{m}$ thick, dense columnar structure, Fm $3 \mathrm{~m}$ cell with lattice parameter of $4.188 \AA$, grain size of $\sim 13 \mathrm{~nm}$, and effective elastic modulus of $580 \mathrm{GPa}$ ) shown in Figure $1(\mathrm{~b})$ with the hardness of $28 \mathrm{GPa}$ exhibited picture frame cracking on the edges of the imprint and inside the imprint itself due to low fracture resistance of both coatings.
The cracking was even more severe in the case of the $\mathrm{TiB}_{2}$ ( $1.2 \mu \mathrm{m}$ thick, dense columnar structure, $\mathrm{P} 6 / \mathrm{mmm}$ cell with lattice parameters of $3.009 \AA, 3.009 \AA$, and $4.276 \AA$, grain size of $\sim 33 \mathrm{~nm}$, and effective elastic modulus of $430 \mathrm{GPa}$ ) with the hardness of $30 \mathrm{GPa}$ shown in Figure 1(c). On the other hand, fracture resistant coatings such as copper are easy to prepare (Figure 1(d); the applied load was lowered to obtain similar indentation depth as in Figures $1(a)-1(c)$ ), but such ductile materials are generally soft- $3 \mathrm{GPa}$ in the presented case-and offer limited wear protection. A new type of materials aptly combining properties of hard and stiff ceramics with ductile and tough metals is highly demanded. Three Mo$\mathrm{B}-\mathrm{C}$ coatings with markedly different microstructures were tailored in the presented study.

Type A coating was composed of $\sim 52$ at. $\%$ Mo, $\sim 24$ at.\% B, and $\sim 24$ at.\% $\mathrm{C}$ and, therefore, had the composition corresponding to the $\mathrm{Mo}_{2} \mathrm{BC}$ stoichiometry.

The XRD diffraction pattern of the type A coating is plotted in Figure 2 in black. The diffraction maxima corresponding to selected pronounced $\mathrm{Mo}_{2} \mathrm{BC}$ (COD card number 5910217) and Mo (COD number 9008474 , PDF card number 00-004-0809) diffractions are plotted with dashed vertical lines and labelled with their Miller indices for reference. The type A coating exhibited one broad peak centred at $38.5^{\circ}$ with the full width at half maximum (FWHM) of $8.2^{\circ}$ and one broad peak at $71.4^{\circ}$ with the FWHM of $10.2^{\circ}$. Such broad diffraction peaks can be attributed to a nearly amorphous microstructure of the coating [14-17]. 


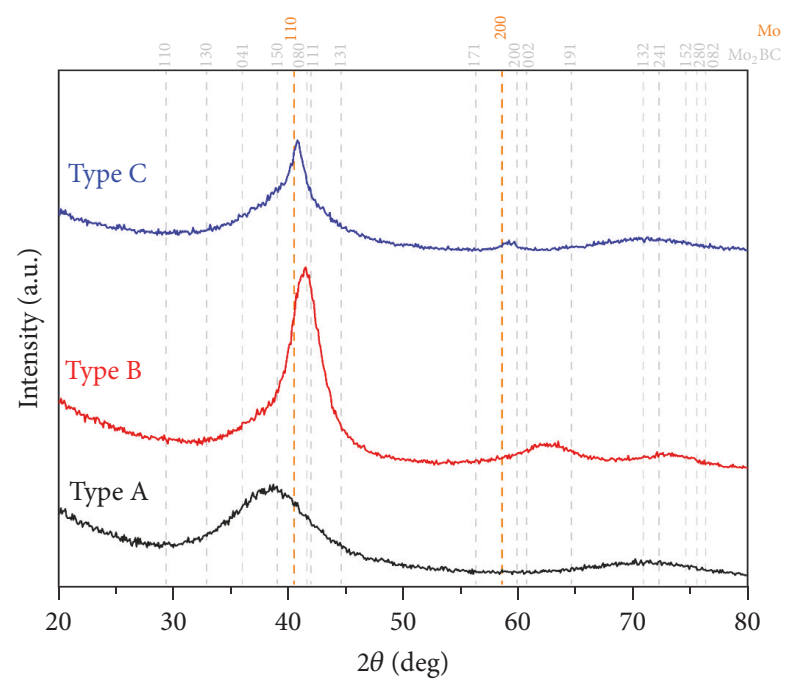

FIGURE 2: GIXRD diffraction patterns of presented Mo-B-C coatings.

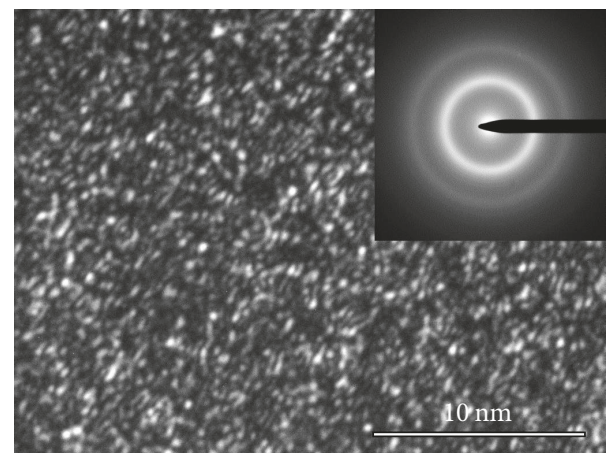

FIGURE 3: Dark field TEM micrograph and corresponding SAED pattern of type A coating.

Dark field transmission electron microscope (TEM) micrograph presented in Figure 3 revealed only short-range ordering in the coating, which was confirmed by SAED. The coating exhibited the hardness and the reduced elastic modulus of $20.5 \pm 0.3 \mathrm{GPa}$ and $350 \pm 5 \mathrm{GPa}$, respectively. A residual indent of the type $A$ coating after indentation with $1 \mathrm{~N}$ load is shown in Figure 4. The coating was tested with the same load as the industrially prepared simple monoblock coatings shown in Figure 1. Lower hardness of the type A coating compared to the industrially prepared coatings with the same thickness of $1.2 \mu \mathrm{m}$ led to a higher indentation depth and therefore to harsher testing conditions. The type A coating exhibited no visible cracks around or inside the area of the residual indentation imprint. This implied excellent fracture resistance, significantly enhanced compared to the TiN, AlTiN, or $\mathrm{TiB}_{2}$ coatings whose residual indents after indentation with the same load and exhibiting pronounced cracking are shown in Figures 1(a)-1(c).

Type B coating was composed of $\sim 52$ at. $\%$ Mo, $\sim 24$ at. $\%$ B, and $\sim 24$ at.\% $\mathrm{C}$ and thus had the same chemical composition as the type A coating. The X-ray diffractogram of the type

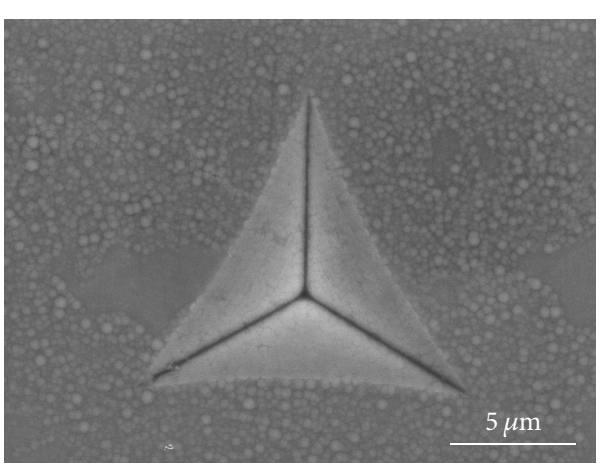

FIGURE 4: A residual indent of type A coating with similar thickness, tested with the same indentation load as the commercial coatings shown in Figures 1(a)-1(c).

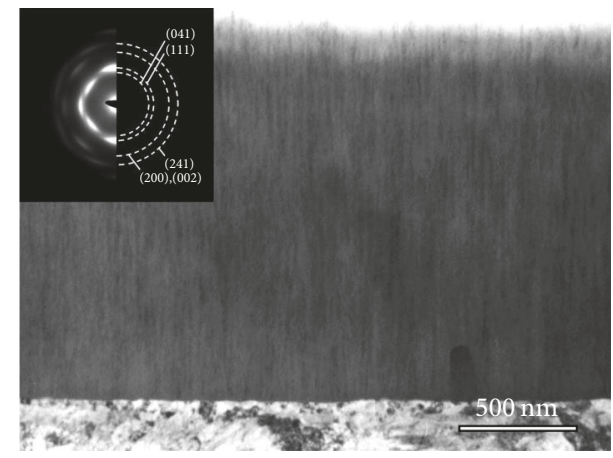

FIGURE 5: Bright field TEM micrograph of type B coating with SAED pattern with identified $\mathrm{Mo}_{2} \mathrm{BC}$ diffraction positions.

B coating exhibited three distinct peaks-the most intense primary peak centred at $41.4^{\circ}$ and two low-intensity peaks at $63.1^{\circ}$ and $73.7^{\circ}$ (see red curve in Figure 2). The asymmetrical main peak can be deconvoluted into two partially overlapping peaks. The base broad peak was similar to the one observed in the type A coating and was centred at $39.7^{\circ}$ exhibiting the FWHM of $10^{\circ}$. This peak implied the presence of a similar, nearly amorphous, phase as in the type A coating. Moreover, an additional peak centred at $41.4^{\circ}$ with the FWHM of $3.5^{\circ}$ emerged and was sharper and more intense compared to type A coating, indicating the presence of another phase with a higher degree of crystallinity. The position of the sharp peak was close to the reference value for (111) and (080) $\mathrm{Mo}_{2} \mathrm{BC}$ diffractions. A bright field TEM image with the corresponding SAED pattern is presented in Figure 5. The coating exhibited a fine columnar microstructure throughout the whole thickness. The SAED pattern was composed of several diffuse rings with a strong texture. These were indexed as corresponding to $\mathrm{Mo}_{2} \mathrm{BC}$ phase according to a simulation of the diffraction ring positions based on ICSD card number 613644 . The individual crystallite size was estimated from the sharp peak of the XRD to be $\sim 4 \mathrm{~nm}$ using the Scherrer equation [18]. Comparing the calculated size and the $\mathrm{Mo}_{2} \mathrm{BC}$ unit cell with the longest side of $\sim 1.8 \mathrm{~nm}$ [1] yielded that the grain was composed of only a few unit cells. This explained the lack of presence of other distinctive high-intensity $\mathrm{Mo}_{2} \mathrm{BC}$ 


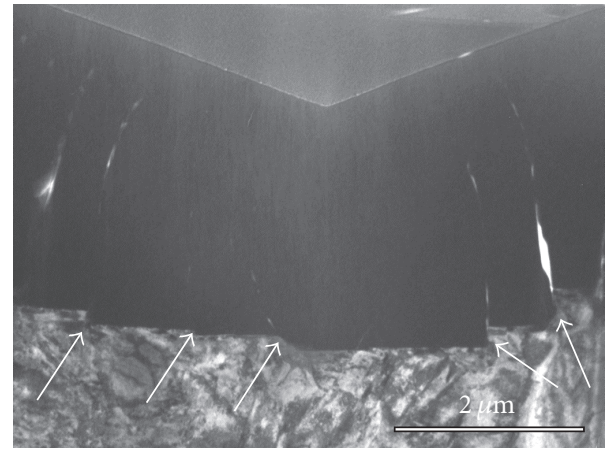

Figure 6: TEM of a lamella cut from a residual imprint after $1 \mathrm{~N}$ indentation to type B coating.

diffraction peaks in the measured diffractograms due to an insufficient continuous periodic structure in each grain. In conclusion, although type A and type B coatings had the same composition, type A coating exhibited just a near-amorphous microstructure, while type $B$ coating was partially crystalline with a possible presence of crystalline $\mathrm{Mo}_{2} \mathrm{BC}$ phase.

Presence of the crystalline $\mathrm{Mo}_{2} \mathrm{BC}$ phase should be advantageous for achieving high hardness as well as fracture resistance of the coating. This is because crystalline $\mathrm{Mo}_{2} \mathrm{BC}$ was shown to exhibit the hardness of $\sim 29 \mathrm{GPa}$ [1]. The type $B$ coating exhibited the hardness and the effective elastic modulus of $26.5 \pm 0.5 \mathrm{GPa}$ and $420 \pm 7 \mathrm{GPa}$, respectively. The surface of the $1 \mathrm{~N}$ residual indent showed no cracking, similarly to the type A coating. The TEM micrograph of a lamella cut from the area of the residual indentation imprint of the coating prepared on the high-speed steel substrate is presented in Figure 6. The high-speed steel substrate sheared in several places under the severe stresses induced by the indentation tests as indicated by the white arrows. The adhesion of the coating to the substrate proved to be higher than its internal cohesion and cracks originated from the coating/substrate interface, specifically from the places of the substrate failure. However, the cracks stopped propagating in the volume of the coating and did not reach its surface. This strongly implies excellent fracture resistance of type B coating.

Type $\mathrm{C}$ coating consisted of $\sim 65$ at. $\% \mathrm{Mo}, \sim 23$ at. $\% \mathrm{~B}$, and $\sim 12$ at.\% $\mathrm{C}$ and thus contained an excess of molybdenum with respect to the previous coatings and to the stoichiometric composition for the $\mathrm{Mo}_{2} \mathrm{BC}$ phase.

The X-ray diffraction pattern of the type $\mathrm{C}$ coating is plotted in blue in Figure 2. The broad background peak centred at $39.5^{\circ}$ exhibited substantial similarity to the type A coating, implying the presence of a near-amorphous structure containing Mo, B, and C. Additionally, a sharp peak centred at $40.7^{\circ}$ was detected. The presence of this peak together with a small peak around $59.3^{\circ}$ indicated the presence of a crystalline Mo phase. The TEM micrograph of a lamella prepared from the type $\mathrm{C}$ coating, which is plotted in Figure 7, revealed predominantly crystalline microstructure with grains exhibiting coarsening with increasing thickness of the coating. The SAED pattern presented in the inset of

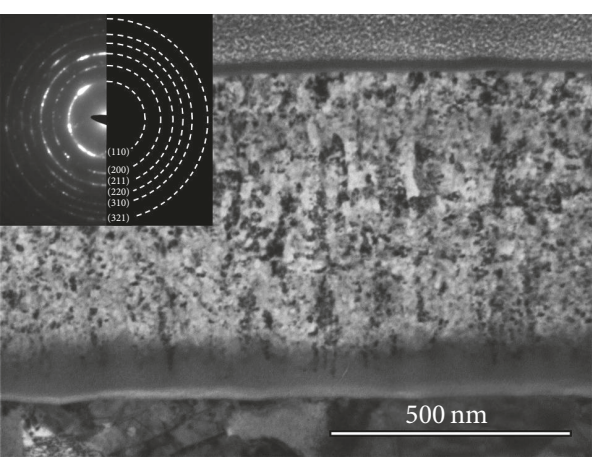

FIGURE 7: TEM image of a lamella cut from the type $\mathrm{C}$ coating with SAED pattern with identified Mo diffraction positions.

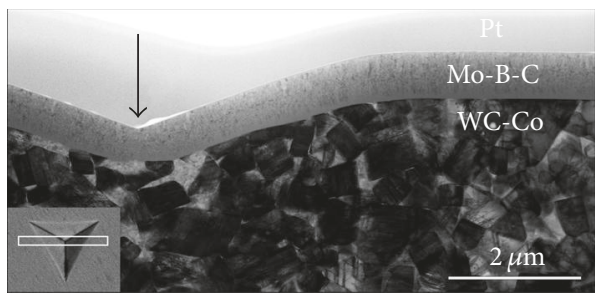

FIgURE 8: TEM of a lamella cut from a residual imprint after $1 \mathrm{~N}$ indentation to type $C$ coating. Inset shows SEM plan view of the residual indentation imprint with marked position of the prepared lamella. The indenter tip position is indicated by the black arrow.

Figure 7 confirmed that the predominant diffraction rings originated from the crystalline Mo phase. The individual Mo crystallite size calculated by the Scherrer equation was $\sim 6 \mathrm{~nm}$. Therefore, based on the TEM and XRD data, the coating can be described as nanocomposite composed of a dominant nanocrystalline Mo phase and a near-amorphous Mo-B-C phase.

The type $\mathrm{C}$ coating exhibited the hardness and the effective elastic modulus of $21.4 \pm 0.9 \mathrm{GPa}$ and $390 \pm 9 \mathrm{GPa}$, respectively. Indentations with $1 \mathrm{~N}$ load were performed on the coating deposited on a cemented tungsten carbide substrate (WC-Co). As in case of previous coating types, no cracks on the surface of the coating were present. A lamella cut by the FIB from the area under the residual indentation imprint is shown in Figure 8 (the specific area where the lamella was cut is shown in the inset). The plastic deformation during the test was so severe that the depth of the residual imprint was approx. 2 times higher than the thickness of the coating. The cemented tungsten carbide substrate was significantly deformed and the coating complied. Despite this large deformation, the coating exhibited excellent adhesion and no delamination under the imprint. Furthermore, no cracks were detected in the bulk of the coating. The predominantly plastic deformation response even under such severe deformation without the presence of cracking in the coating proved excellent fracture resistance of type $\mathrm{C}$ coating.

All three designs of the Mo-B-C coatings exhibited high fracture resistance impossible to be met with current state-ofthe-art protective coatings. The presented Mo-B-C coatings 
exhibited a compressive stress of $\sim 1 \mathrm{GPa}$. The commercially prepared coatings exhibited similar levels of compressive stress of $\sim 0.5-2 \mathrm{GPa}$. Therefore, the enhancement of the fracture toughness of the Mo-B-C coatings was not due to higher levels of compressive stress inhibiting crack formation and propagation. Also, since the microstructure of the Mo-B-C coatings ranged from nearly amorphous through nanocomposite to prevalently crystalline, the observed high fracture resistance cannot be attributed to their particular microstructure. All of these coatings, however, contained various amounts of the near-amorphous Mo-B-C tissue phase. We suppose that there existed the advantageous shortrange ordering in the near-amorphous tissue phase which has a similar bond arrangement to that found in the crystalline $\mathrm{Mo}_{2} \mathrm{BC}$ phase where metallic bonds provide ductility and high fracture resistance [1]. Whereas this tissue phase ensures fracture resistance, the addition of a crystalline phase positively influences the mechanical properties of the resulting nanocomposite.

The ratio of the elastic work to the total indentation work measured for the load of $5 \mathrm{mN}$ was similar for all presented designs of Mo-B-C coatings-48\% for the type A and $\mathrm{B}$ coatings and $47 \%$ for the type $\mathrm{C}$ coating. Therefore, for low loads the deformation is elastoplastic and the observed plastic deformation behavior of the coatings is not the result of the substrate deformation. All the presented Mo-B-C coating designs exhibited the high hardness of $\sim 20-27 \mathrm{GPa}$ and the effective elastic modulus of $\sim 350-420 \mathrm{GPa}$. Due to the predominantly amorphous nature of the type A coating, it exhibited the lowest hardness and the lowest effective elastic modulus of $20.5 \pm 0.3 \mathrm{GPa}$ and $350 \pm 5 \mathrm{GPa}$, respectively. However, the hardness of $>20 \mathrm{GPa}$ still classified the type A coating as a hard coating. The deformation mechanism in the type A coating is due to its amorphous nature, similar to deformation mechanisms in metallic glasses and it is possible to describe it using the free volume model proposed in [19].

The presence of a crystalline phase in the type B coating led to the hardness increase of $\sim 30 \%$ and the effective elastic modulus increase of $\sim 20 \%$ compared to the type A coating without reducing its high fracture resistance. The hardness and the effective elastic modulus of $26.5 \pm 0.5 \mathrm{GPa}$ and $420 \pm$ $7 \mathrm{GPa}$, respectively, were achieved in the case of the type $\mathrm{B}$ coating. The increase of the hardness and the elastic modulus originated from the presence of larger $\mathrm{Mo}_{2} \mathrm{BC}$ crystalline grains and the physical effect of nanocomposite hardening [4] and the Hall-Petch effect $[5,6]$. The dominating mechanisms that contribute to the plastic deformation in the type $\mathrm{B}$ coating are grain boundary sliding, grain rotation, and grain rearrangement in the Mo-B-C amorphous matrix.

The type $\mathrm{C}$ coating was designed to contain a higher amount of the inherently ductile crystalline metallic component. The increased amount of molybdenum led to the formation of high amounts of crystalline Mo phase. As pure Mo exhibits the hardness of only $<10 \mathrm{GPa}$ [11], the hardness of type $\mathrm{C}$ coating was $21.4 \pm 0.9 \mathrm{GPa}$, and the effective elastic modulus was $390 \pm 9 \mathrm{GPa}$. In the type $\mathrm{C}$ coating, which contains nanocrystallites with the grain size of $\sim 6 \mathrm{~nm}$, the plasticity is confined almost entirely to the grain boundaries with grain boundary migration and grain rotation/sliding as the primary mechanisms contributing to the plastic deformation, similarly to the case of superplastic materials. The shear stress at the interface is 2-3 times higher than the highest shear stress in a homogeneous material [20]. Thus, grain boundary ledges and grain boundary dislocations can initiate plastic deformation.

\section{Conclusions}

In summary, we presented different designs of Mo-B-C coatings. The deposited coatings exhibited different relative amounts of crystalline and amorphous phases. All of the presented coating designs exhibited significantly reduced cracking compared to standard protective coatings such as TiN, AlTiN, or $\mathrm{TiB}_{2}$ while simultaneously preserving hardness > $20 \mathrm{GPa}$. The hardness was governed by the relative amount of the nanocrystalline and near-amorphous phases and the maximum value of $27 \mathrm{GPa}$ was achieved for nanocomposite structure containing $\mathrm{Mo}_{2} \mathrm{BC}$ grains embedded in Mo-B$\mathrm{C}$ tissue phase. No cracks in/around the area of residual imprints made by $1 \mathrm{~N}$ load were detected in the case of all the presented designs of the Mo-B-C coatings, whereas stateof-the-art monoblock protective coatings with similar thickness and comparable levels of compressive stress failed and exhibited severe cracking. Cracks in the bulk of the deposited Mo-B-C coatings were detected only if the substrate itself sheared. If the substrate was plastically deformed without shearing, the coating complied, and no cracks in the bulk of the coating were detected. Such coating material can pave the way to the next generation of protective coatings for the most demanding applications where deformation of the coated workpiece is involved.

\section{Conflicts of Interest}

The authors declare that they have no conflicts of interest.

\section{Acknowledgments}

This research has been supported by project LO1411 (NPU I) and GACR Project 15-17875S. The RBS analyses were realized at CANAM (Center of Accelerators and Nuclear Analytical Methods) under Grants LM 2011019 and LM 2015056. The authors would like to acknowledge SHM, s.r.o., for industrial preparation of the monoblock protective coatings used for illustration.

\section{References}

[1] J. Emmerlich, D. Music, M. Braun, P. Fayek, F. Munnik, and J. M. Schneider, "A proposal for an unusually stiff and moderately ductile hard coating material: Mo2BC," Journal of Physics D: Applied Physics, vol. 42, no. 18, Article ID 185406, 2009.

[2] H. Bolvardi, J. Emmerlich, M. To Baben et al., "Systematic study on the electronic structure and mechanical properties of X2BC (X = Mo, Ti, V, Zr, Nb, Hf, Ta and W)," Journal of Physics: Condensed Matter, vol. 25, no. 4, Article ID 045501, 2013.

[3] S. Zhang, D. Sun, Y. Fu, and H. Du, "Recent advances of superhard nanocomposite coatings: A review," Surface and Coatings Technology, vol. 167, no. 2-3, pp. 113-119, 2003. 
[4] S. Veprek, R. F. Zhang, M. G. J. Veprek-Heijman, S. H. Sheng, and A. S. Argon, "Superhard nanocomposites: Origin of hardness enhancement, properties and applications," Surface and Coatings Technology, vol. 204, no. 12-13, pp. 1898-1906, 2010.

[5] E. O. Hall, "The deformation and ageing of mild steel: III discussion of results," Proceedings of the Physical Society, Section $B$, vol. 64, no. 9, pp. 747-752, 1951.

[6] N. J. Petch, “The cleavage strength of polycrystals," Journal of the Iron and Steel Institute, vol. 174, pp. 25-28, 1953.

[7] H. Ramezanalizadeh, M. Emamy, and M. Shokouhimehr, "A novel aluminum based nanocomposite with high strength and good ductility," Journal of Alloys and Compounds, vol. 649, pp. 461-473, 2015.

[8] T. Borkar, H. Mohseni, J. Hwang et al., "Excellent strengthductility combination in nickel-graphite nanoplatelet (GNP/Ni) nanocomposites," Journal of Alloys and Compounds, vol. 646, Article ID 34351, pp. 135-144, 2015.

[9] J. W. Bradley, H. Bäcker, Y. Aranda-Gonzalvo, P. J. Kelly, and R. D. Arnell, "The distribution of ion energies at the substrate in an asymmetric bi-polar pulsed DC magnetron discharge," Plasma Sources Science and Technology, vol. 11, no. 2, pp. 165-174, 2002.

[10] J. Vlček, A. D. Pajdarová, and J. Musil, "Pulsed dc magnetron discharges and their utilization in plasma surface engineering," Contributions to Plasma Physics, vol. 44, no. 5-6, pp. 426-436, 2004.

[11] Y. T. Pei, C. Q. Chen, K. P. Shaha et al., "Microstructural control of TiC/a-C nanocomposite coatings with pulsed magnetron sputtering," Acta Materialia, vol. 56, no. 4, pp. 696-709, 2008.

[12] Y. Yang and M. Nastasi, Handbook of Modern Ion Beam Materials Analysis, Material Research Society, Pittsburgh, PA, USA, 2009.

[13] W. C. Oliver and G. M. Pharr, "Measurement of hardness and elastic modulus by instrumented indentation: advances in understanding and refinements to methodology," Journal of Materials Research, vol. 19, no. 1, pp. 3-20, 2004.

[14] N. S. Murthy and H. Minor, "General procedure for evaluating amorphous scattering and crystallinity from X-ray diffraction scans of semicrystalline polymers," Polymer Journal, vol. 31, no. 6, pp. 996-1002, 1990.

[15] A. Guinier, "X-ray Diffraction: In Crystals, Imperfect Crystals, and Amorphous Bodies," General Publishing Company, pp. 55150, 1994.

[16] L. Zábranský, V. Buršíková, P. Souček, P. Vašina, and J. Buršík, "On the study of the mechanical properties of Mo-B-C coatings," EPJ Applied Physics, vol. 75, no. 2, Article ID 24716, 2016.

[17] L. Zábranský, V. Buršíková, P. Souček et al., “Thermal stability of hard nanocomposite Mo-B-C coatings," Vacuum, vol. 138, pp. 199-204, 2017.

[18] P. Scherrer, "Bestimmung der Grosse und der Inneren Struktur von Kolloidteilchen Mittels Rontgensrahlen," Nachrichten von der Gesellschaft der Wissenschaften, Gottingen. MathematischPhysikalische Klasse, pp. 98-100, 1918.

[19] F. Spaepen, "A microscopic mechanism for steady state inhomogeneous flow in metallic glasses," Acta Metallurgica et Materialia, vol. 25, no. 4, pp. 407-415, 1977.

[20] M. A. Meyers, A. Mishra, and D. J. Benson, "Mechanical properties of nanocrystalline materials," Progress in Materials Science, vol. 51, no. 4, pp. 427-556, 2006. 


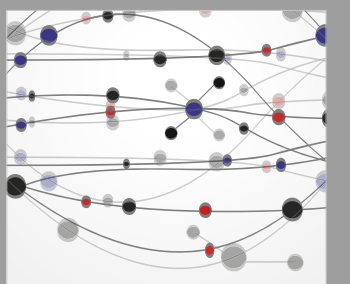

The Scientific World Journal
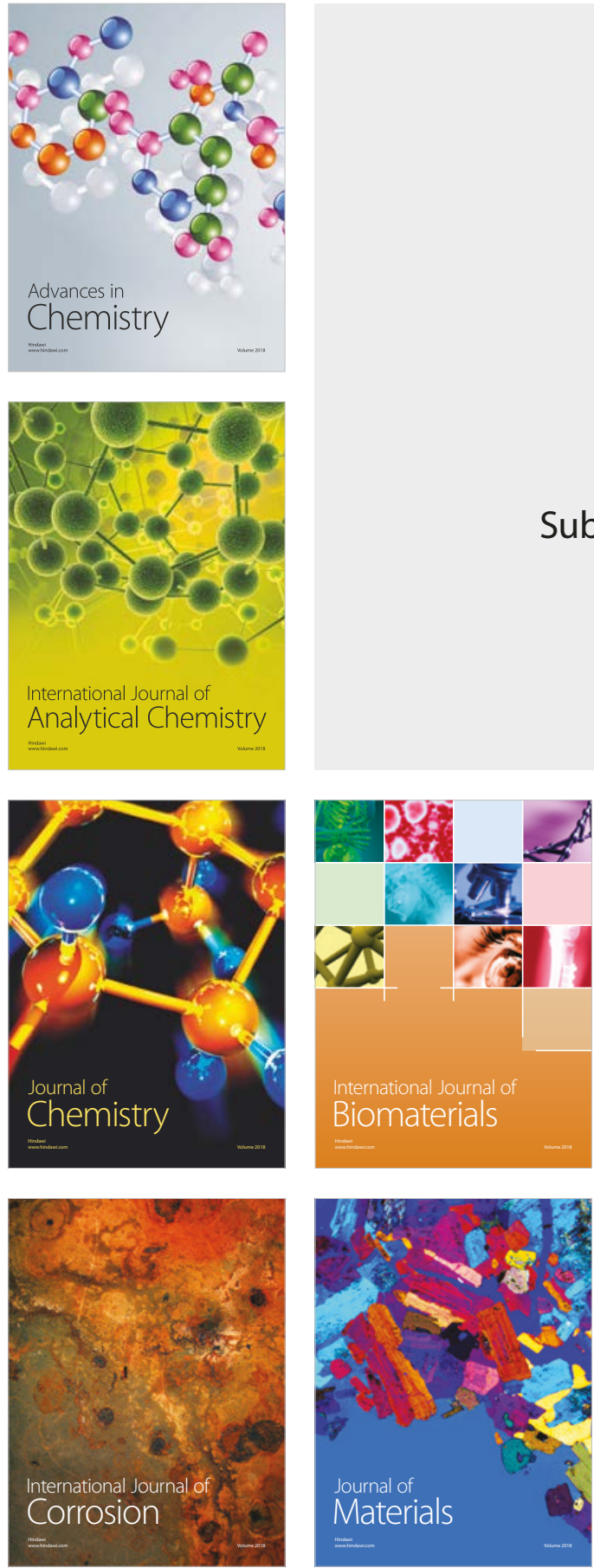

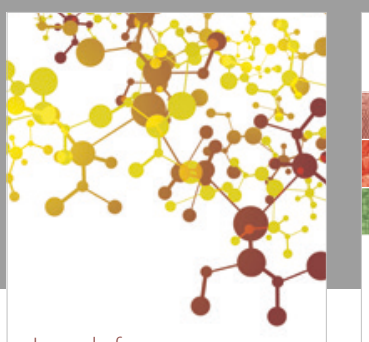

Journal of

Applied Chemistry
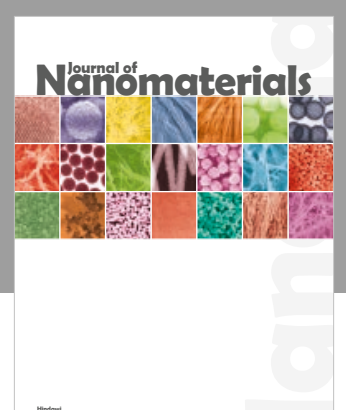

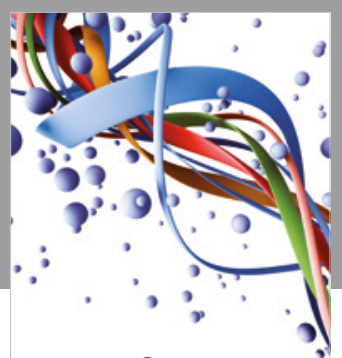

Scientifica

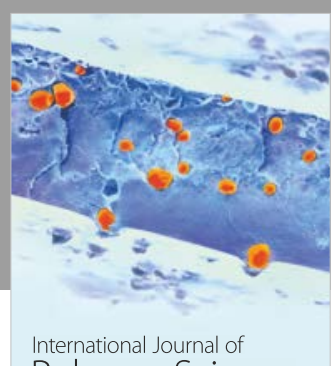

Polymer Science

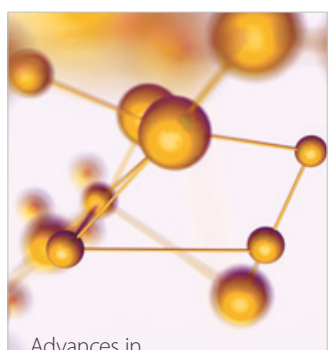

Physical Chemistry
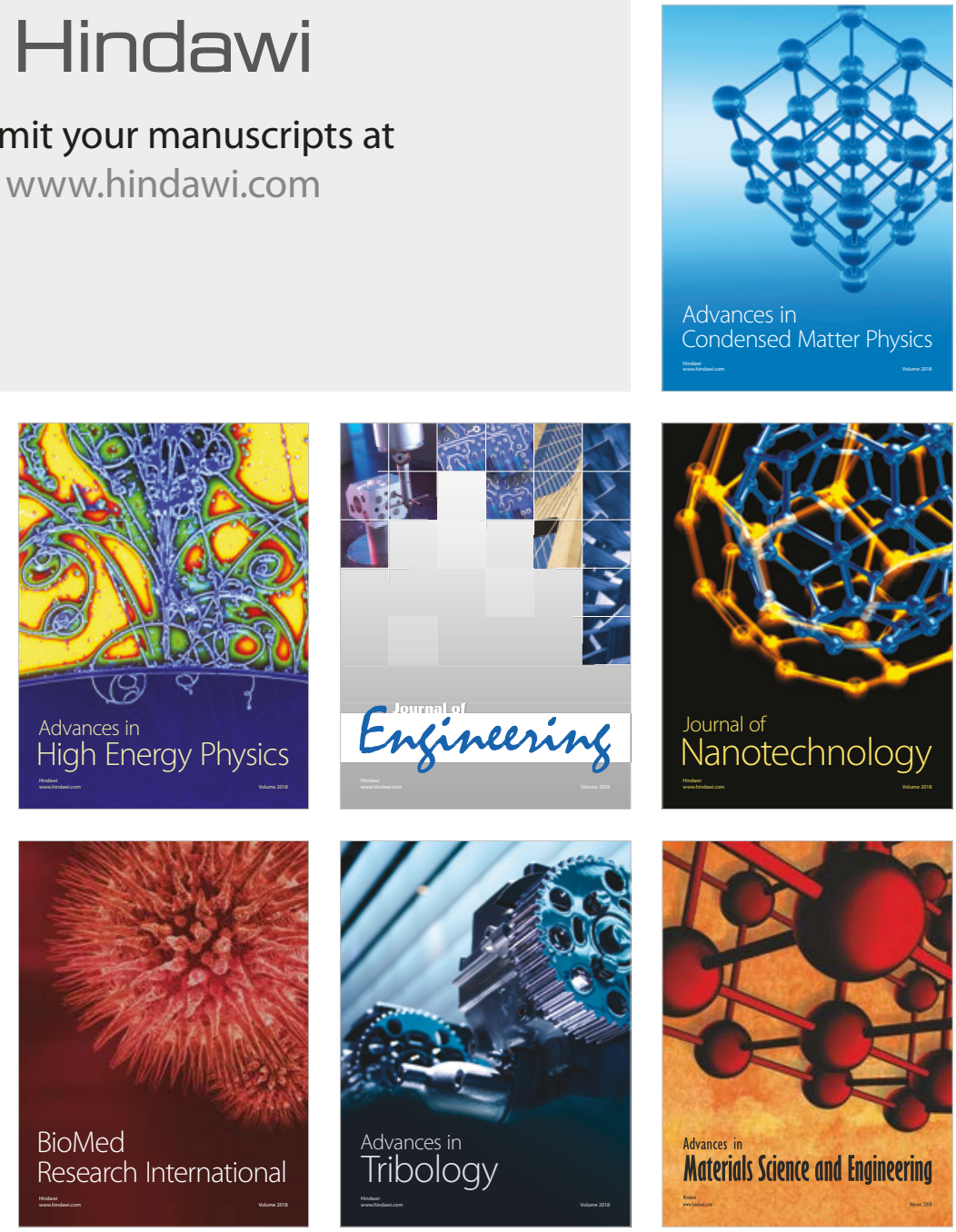